\title{
Altered expression of epigenetic modifiers EZH2, H3K27me3, and DNA methyltransferases in meningiomas - prognostic biomarkers for routine practice
}

\author{
Swagatika Samal ${ }^{1}$, Ashis Patnaik ${ }^{2}$, Fakir Mohan Sahu ${ }^{2}$, Suvendu Purkait ${ }^{1}$ \\ ${ }^{1}$ Department of Pathology, All India Institute of Medical Sciences, Bhubaneswar, India, ${ }^{2}$ Department of Neurosurgery, All India Institute \\ of Medical Sciences, Bhubaneswar, India
}

\begin{abstract}
Introduction: Meningiomas comprises of a wide variety of histological entities with heterogeneous biological behaviour and prognosis. The plethora of genetic data are yet to produce relevant biomarkers for routine use. In contrast, epigenetic alterations are less elucidated.

Material and methods: The expression of the key molecules involved in the two principal epigenetic systems, i.e. DNA methylation (DNA methyltransferases [DNMT-1, -3A and -3B]) and histone modification (Enhancer of Zeste homolog-2 [EZH2] and trimethyl histone-3 [H3K27me3]) were assessed in 149 cases of meningiomas (grade I - 102, grade II - 47) by immunohistochemistry.

Results: Immunopositivity for EZH2 (38.3\% vs. 6.0\%) and negativity for H3K 27 me $3(10.6 \%$ vs. 1.0\%) were significantly more common in grade II tumours. Both were associated with significantly higher proliferative activity. The majority of the cases of both grades showed expression of all three DNMTs. However, high expression of DNMT-1 was significantly more common in grade II tumours (87.8\% vs. 66.2\%). Expression of EZH 2 and loss of H3K 27 me 3 were associated with significantly shorter progression-free survival (hazard ratio [HR] $=4.07$ and 0.24 , respectively).

Conclusions: The key epigenetic regulators play important roles in the pathobiology of meningiomas. EZH 2 positivity and H3K27me 3 negativity are associated with aggressive tumour-biology and poor prognosis. Both these markers can easily be assessed by immunohistochemistry and can be incorporated in routine practice.
\end{abstract}

Key words: meningioma, epigenetic, H3K27me3, EZH2, DNMT.

\section{Introduction}

Meningiomas are the most frequently diagnosed primary brain tumours [15]. The majority of meningiomas (approx. 80\%) have benign clinical behaviour and can be treated by surgery alone. The remaining $20 \%$ usually recur after surgical resection and need adjuvant treatments [4,10]. The World Health Organisation (WHO) classification recognises 15 subtypes of meningiomas sub-divided into three histological grades. This classification system is based on the histomorphological features and probably the best available algorithm for risk stratification in current 
practice [9]. In addition to grade, the location of tumour, accessibility to complete surgical resection, and infiltration to other structures, such as dura, are also important prognostic factors. However, the clinical outcome in meningioma cases does not always correlate with the histological features. Some of the grade I meningiomas can have local infiltration and higher recurrence rate while high-grade cases may have indolent nature [4]. The basis of the morphological and behavioural discrepancies is not well established.

During the last decade, the analysis of epigenetic dysregulation in cancer was at the forefront of cancer research. DNA methylation and histone modifications are the two principal epigenetic phenomena [20]. Recent high throughput studies have led to conduction of the whole genome methylation profiling with the proposition of various DNA methylation subgroups for risk stratification of meningioma cases. This subgrouping provides a more precise prediction of clinical outcomes as compared to the WHO grading system and is of great help in clinical decision making [19]. DNA methyltransferases (DNMTs) are a group of enzymes that catalyse the transfer of a methyl moiety to the $\mathrm{CpG}$ dinucleotide and are responsible for the establishment and regulation of global patterns of DNA methylation [18]. Although methylation profiling in meningioma is well documented, the role of DNMTs is yet to be well elucidated. The other important arm of epigenetics is histone modification. It is believed that DNA methylation and histone methylation are tied together in a reinforcing loop where one modification depends on the other. The level of histone methylation is regulated by the polycomb repressive complex (PRC) to a major extent. Enhancer of Zeste homolog 2 $(E Z H 2)$, the catalytic subunit of PRC2, is the most deregulated and studied epigenetic modifier in the context of tumour biology. It is responsible for the trimethylation of histone 3 at its lysine residue (H3K27), which is an important histone modification responsible for inhibiting gene expression [1,12,22]. Although altered expression of EZH2 and H3K27me3 have been described in various solid and haematological malignancies, there is a dearth of literature in meningiomas $[2,5,13]$. A recent study documented transcriptional evidence of increased PRC2 activity in a specific subgroup of aggressive anaplastic meningiomas (WHO grade III) [3]. On the other hand, loss of expression of $\mathrm{H} 3 \mathrm{~K} 27 \mathrm{me} 3$ was found to be associ- ated with a poor prognosis in grade I/II meningiomas [7]. Hence, there may be large-scale deregulation of epigenetic pathways in meningiomas involving both the DNA methylation and histone modification system. In the present study, we intended to assess the expression of the important key enzymes of DNA methylation (DNMTs), histone modification system $(\mathrm{EZH} 2)$, and histone mark (H3K27me3) in cases of meningioma, to ascertain their possible role in meningeal tumourigenesis and in determining patient outcome.

\section{Material and methods}

An observational study was carried out including retrospectively diagnosed cases of meningiomas from the archives of the Department of Pathology, AllMS, Bhubaneswar. Ethical approval was obtained from the Institutional Ethical Committee. A total of 149 cases of meningiomas were included (2015-2018). The haematoxylin and eosin stained slides of all the cases were reviewed for confirmation of the diagnosis and histological sub-typing as per WHO 2016.

\section{Immunohistochemical analysis}

Immunohistochemical analysis was performed in tissue microarray ( $5 \mathrm{~mm}$ and $3 \mathrm{~mm}$ [UNITMA, Korea]) as well as in whole sections using primary antibodies against EZH2, H3K27me3, DNMT-1, DNMT-3A, and DNMT-3B. The details of these antibodies are provided in Table I. The TMA was constructed using 1-3 tumour tissue cores from different areas of each case, depending upon the morphological heterogeneity and invasion for adequate representation. For all the immunohistochemical marker analysis on whole sections was done in 10 randomly selected cases with different level of expression. Additionally, in all negative cases of H3K27me3 analysis on whole sections were performed. Serial 3-4 $\mu \mathrm{m}$ thick sections were cut from the representative paraffin blocks and mounted on poly-L-lysine coated slides followed by fixation on a hot plate. The slides were then deparaffinised and rehydrated. Antigen retrieval was performed in a 600-watt microwave oven for 30 min using 0.01 $\mathrm{mol} / \mathrm{l}$ citrate buffer ( $\mathrm{pH}$ 6.0). Peroxidase blocking was done with $3 \% \mathrm{H}_{2} \mathrm{O}_{2}$ in methanol for $30 \mathrm{~min}$. The sections were then incubated with adequately diluted primary antibodies (Table I) in a humidity chamber for two hours. Sections were then washed in Tris-buffer and treated with the biotin-labelled secondary 
Table I. Details of the primary antibody used

\begin{tabular}{|lccccc|}
\hline Primary antibody & Company & Antigen retrieval buffer & Dilution & Localisation & Positive control \\
\hline DNMT-1 & Sigma Aldrich, Sweden & Citrate & $1: 200$ & Nucleus & Normal testis \\
\hline DNMT-3A & Sigma Aldrich, Sweden & Citrate & $1: 50$ & Nucleus & Reactive lymph node \\
\hline DNMT-3B & Sigma Aldrich, Sweden & Citrate & $1: 200$ & Nucleus & Normal testis \\
\hline EZH2 & $\begin{array}{c}\text { Cell Signalling } \\
\text { technology, } \\
\text { Danvers, MA }\end{array}$ & Citrate & $1: 500$ & Nucleus & Carcinoma breast, high grade \\
\hline H3K27me3 & $\begin{array}{c}\text { Cell Signalling } \\
\text { technology, } \\
\text { Danvers, MA }\end{array}$ & Citrate & $1: 500$ & Nucleus & Reactive lymph node \\
& & & & \\
\hline
\end{tabular}

antibody for $60 \mathrm{~min}$ at room temperature followed by another wash. The sections were incubated with peroxidase-conjugated streptavidin for 30 minutes at room temperature. Then the slides were rinsed with three changes of Tris- $\mathrm{HCl}$ buffer. This was followed by diaminobenzidine staining under microscopic control. The slides were then washed with distilled water, counterstained in haematoxylin for $1 \mathrm{~min}$, and mounted. A positive control was included in all tissue microarrays to assess the quality of staining.

\section{Quantification of immunohistochemistry}

Scoring was performed by two experienced pathologists (S.P., S.S.) independently blinded to the clinicopathological information. A labelling index was calculated in each case as a percentage of positively stained nuclei. For this, the slides were scanned under 40 magnification to look for the distribution of the staining and the hot spot (areas with maximum proportion of positive cells). At least 1000 tumour cells were counted under $\times 400$ magnification starting with the hot spot. The vascular endothelial cells and inflammatory cells were carefully excluded while counting morphologically. The percentage positivity and the intensity of immunostaining were evaluated to form a semi-quantitative scoring. The labelling index was further sub-grouped as 0 for < $5 \%$ of positive cells, 1 for $5 \%$ to $25 \%$ of positive cells, 2 for $26 \%$ to $50 \%$ of positive cells, and 3 for $>50 \%$ of positive cells. The staining intensity was also scored as - 0 for no staining, 1 for weak staining, 2 for moderate staining, and 3 for strong staining. In the case of heterogeneity of staining intensity, the intensity of the major proportion of cell were considered. The final immunostaining score was calculated by multiplying the percentage score with the intensity score. Hence, the minimum score was 0 and the maximum score was 9. Based on the multiplication score, the cases were subdivided into three groups - a score of 0 was regarded as negative, 1-4 as low expression, and 5-9 as high expression. In cases of negative staining for $\mathrm{H} 3 \mathrm{~K} 27 \mathrm{me} 3$ in TMA, a repeat immunohistochemistry was performed on the whole sections to identify/rule out focal positivity. In cases of loss of immune-expression, concordance of opinion was achieved in all cases. A good concordance (> 95\%) was also achieved in subdividing the cases into low and high expression. In discrepant cases a third pathologist was consulted (S.M.), and his opinion was taken into account.

\section{Statistical analysis}

Statistical tests were performed using SPSS version 23.0 software (SPSS Inc., Chicago, IL, USA) and Microsoft Excel. The relationships between the qualitative variables were assessed by $\chi^{2}$ and Fisher's exact test.

Progression-free survival was calculated from the date of surgery to the date of recurrence (clinical/ radiological) or death due to disease. Patients who did not show any evidence of recurrence at the last follow-up were considered as a censored event in the analysis. To assess clinicopathological and/or molecular alteration associated with progression- free survival (PFS), survival curves were calculated according to the Kaplan-Meier method, and the differences between curves were assessed using the log-rank test. In all analyses, two-sided $p$ values $<0.05$ were considered significant.

\section{Results}

The median age at diagnosis in the present series was 50 years (range 11-85 years). Only four cases were in the paediatric age group ( $\leq 18$ years). 
Table II. Clinicopathological features of the meningioma cases

\begin{tabular}{|c|c|c|}
\hline Features & Grade I [n (\%)] & Grade II $[n(\%)]$ \\
\hline No. of cases & $102(68.5 \%)$ & 47 (31.5\%) \\
\hline $\begin{array}{l}\text { Histological } \\
\text { subtype }\end{array}$ & $\begin{array}{c}\text { Meningothelial - } 49(48 \%) \\
\text { Transitional - } 33(32.4 \%) \\
\text { Fibroblastic - } 7(6.9 \%) \\
\text { Psammomatous - } 7(6.9 \%) \\
\text { Angiomatous - 3 }(3 \%) \\
\text { Microcystic - 2 (2\%) } \\
\text { Secretory - 2 (2\%) }\end{array}$ & $\begin{array}{c}\text { Atypical - } \\
46(97.9 \%) \\
\text { Clear cell - } \\
1(2.1 \%)\end{array}$ \\
\hline $\begin{array}{l}\text { Age } \\
\text { [mean (range)] }\end{array}$ & $\begin{array}{c}48.9 \text { yrs } \\
(11-85 \text { yrs })\end{array}$ & $\begin{array}{c}50.7 \mathrm{yrs} \\
(16-75 \mathrm{yrs})\end{array}$ \\
\hline$M: F$ & $1: 2.4$ & $1: 1.7$ \\
\hline Site & $\begin{array}{c}\text { Convexity }-63(61.8 \%) \\
\text { Skull base }-31(30.4 \%) \\
\text { Spinal }-8(7.8 \%)\end{array}$ & $\begin{array}{c}\text { Convexity- } \\
36(76.6 \%) \\
\text { Skull base- } \\
10(21.3 \%) \\
\text { Spinal - } 1(2.1 \%)\end{array}$ \\
\hline $\begin{array}{l}\text { MIB-1 labelling } \\
\text { index } \\
(\text { mean } \pm \text { SD) }\end{array}$ & $2.9 \pm 1.7$ & $7.0 \pm 5.8$ \\
\hline $\begin{array}{l}\text { Estimated } \\
\text { mean PFS }\end{array}$ & 222.9 weeks & 161.4 weeks \\
\hline
\end{tabular}

We subdivided the cases into younger ( $\leq 40$ years) and older ( $>40$ years) age groups, similar to previous studies $[16,21]$. The older age group constituted the majority (78\%). There was a female preponderance $(\mathrm{M}: \mathrm{F}-1: 2.1)$. Out of the 149 cases included, 102 $(68 \%)$ cases were WHO grade I while the remaining $47(32 \%)$ were WHO grade II. No cases of grade III meningioma were included in the study. The clinicopathological features of grade I and II meningiomas are listed in Table II. Brain invasion was identified in 27 (19.4\%) cases, out of which 20 cases additionally showed cellular morphological features of grade II meningiomas. In the remaining seven cases WHO grade II was assigned based solely on the brain invasion. Immunopositivity for progesterone receptor was identified in $85 \%$ cases and was more frequent in lower grades ( $87.1 \%$ vs. $79.4 \%)$. The MIB-1 labelling index (LI) ranges from $1 \%$ to $30 \%$. A cut-off of $4 \%$ was used to classify the cases into low $(\leq 4 \%)$ and high ( $>4 \%$ ) proliferative groups [9].

\section{EZH2 immunohistochemistry}

Immunohistochemical expression of EZH2 was found to be significantly more common in grade II tumours as compared to their lower-grade counterparts $(38.3 \%$ vs. $6.0 \% ; p<0.001)$ (Fig. 1$)$. The majority of the positive cases showed a low level of expression. Strong expression of EZH 2 was detected in only two cases, both of which were of grade II histologically (Table III). The immunopositivity was accentuated in the areas with high proliferative activity. Meningiomas located in the convexities more frequently showed EZH2 expression as compared to skull-base cases $(19.5 \%$ vs. $6.3 \% ; p=0.1)$. The spinal cases also showed a higher frequency of EZH2 expression (22.2\%), similar to the convexity meningiomas. Interestingly, none of the cases of grade II meningioma that were diagnosed solely based on the brain invasion showed EZH2 positivity, while $45 \%$ of the other grade II cases were positive for EZH2 $(p=0.034)$. The proliferative activity (MIB-1 LI) of the cases showing EZH2 expression was significantly higher as compared to negative cases (mean \pm SD $-7.9 \pm 6.2$ vs. $3.7 \pm 3.3 ; p<0.001$ ). Approximately $81 \%$ of cases with EZH2 expression showed a high MIB-1 labelling index ( $\geq 4 \%$ ), while it was only $33 \%$ in EZH2-negative cases. Necrosis was also found to be significantly more common in EZH2-positive cases (29\% vs. $6.2 \%$; $p=0.003)$. There was no significant association of $\mathrm{EZH} 2$ expression with brain invasion within grade II cases. Cases with $\mathrm{EZH} 2$ positivity showed a lower frequency of PR expression as compared to the negative cases $(72.2 \%$ vs. $87.0 \% ; p=0.11)$. No significant associations with any other specific histological subtype or any other clinicopathological parameters were identified.

\section{H3K27me3 immunohistochemistry}

Different and distinct patterns of staining were noted, including diffusely positive, admixture of positive and negative fragments, intermixed mosaic, and loss of staining. Initially, a total of 17 cases showed immunonegativity for H3K27me3 staining on TMA (diameter $-5 \mathrm{~mm}$ ) sections. In all these cases internal controls (endothelial cells and/or lymphocytes) were positive. Interestingly, when the staining was repeated on the whole section (minimum dimension $2 \mathrm{~cm}^{2}$ ), only six cases showed complete loss of staining in the tumour cell with the presence of internal positive control. These cases were finally considered as true negative. In contrast to EZH2, loss of H3K27me3 staining appeared to be more important in the context of tumour biology of meningiomas. Loss of staining was significantly more frequent in higher grade tumours $(10.6 \%$ 



Fig. 1. Photomicrographs showing immunohistochemical expression of EZH2 [negative (A), low expression (B) and high expression (C)], H3K27me3 [negative with positivity in endothelium (arrow) (D), low/heterogenous expression (E) and high expression (F)], DNMT-1 [negative $(\mathbf{G})$ and positive/high (H)], DNMT-3B 1 [negative (I) and positive/high (J)], and DNMT-3A 1 [negative (K) and positive/high (L)].

vs. $1.0 \% ; p=0.013$ ) (Table III, Fig. 1). However, within the grade II tumours there was no significant difference between cases that were diagnosed based on brain invasion and other cases $(14.3 \%$ vs. $10 \%$; $p=0.57)$. Cases with loss of H3K $27 \mathrm{me} 3$ were associated with a significantly higher proliferative activity as compared to positive cases. (MIB-1 labelling index $[$ mean $\pm S D-12.2 \pm 10.9$ vs. $4.1 \pm 3.4 ; p=0.027]$ ).
All but one cases with H3K27me3 loss showed a higher MIB-1 labelling index $\geq 4 \%$. None of the young adult cases ( $\leq 40$ years) showed a loss of staining. Although meningioma cases with convexity location, necrosis, brain invasion, and PR negativity more commonly showed loss of H3K27me3 staining, the differences were not statistically significant. 
Table III. Expression of EZH2, H3K27me3, and DNMT proteins in different grades of meningiomas

\begin{tabular}{|c|c|c|c|c|}
\hline Markers & Expression & WHO grade I & WHO grade II & $p$-value \\
\hline \multirow[t]{3}{*}{$\mathrm{EZH} 2$} & Negative & $94.0 \%(94 / 100)$ & $61.7 \%(29 / 47)$ & \multirow{3}{*}{$\begin{array}{l}\text { Immunopositivity in grade } \\
\text { I vs. II } p<0.001^{*}\end{array}$} \\
\hline & Low & $6.0 \%(6 / 100)$ & $34.0 \%(16 / 47)$ & \\
\hline & High & 0 & $4.2 \%(2 / 47)$ & \\
\hline \multirow[t]{3}{*}{ H3K27me3 } & Negative & $1.0 \%(1 / 100)$ & $10.6 \%(5 / 47)$ & \multirow{3}{*}{$\begin{array}{l}\text { Immunonegativity in grade } \\
\text { I vs. II } p=0.013^{*}\end{array}$} \\
\hline & Low & $9.0 \%(9 / 100)$ & $8.6 \%(4 / 47)$ & \\
\hline & High & $90.0 \%(90 / 100)$ & $80.8 \%(38 / 47)$ & \\
\hline \multirow[t]{3}{*}{ DNMT-1 } & Negative & $4.2 \%(3 / 71)$ & $7.3 \%(3 / 41)$ & \multirow{3}{*}{$\begin{array}{l}\text { High expression in grade } \\
\qquad \text { I vs. II } p=0.013^{*}\end{array}$} \\
\hline & Low & $29.6 \%(21 / 71)$ & $4.9 \%(2 / 41)$ & \\
\hline & High & $66.2 \%(47 / 71)$ & $87.8 \%(36 / 41)$ & \\
\hline \multirow[t]{3}{*}{ DNMT-3A } & Negative & $25.0 \%(12 / 48)$ & $28.6 \%(8 / 28)$ & \multirow{3}{*}{$\begin{array}{l}\text { No significant difference } \\
\text { between grade I vs. II }\end{array}$} \\
\hline & Low & $33.3 \%(16 / 48)$ & $25.0 \%(7 / 28)$ & \\
\hline & High & $41.7 \%(20 / 48)$ & $46.4 \%(13 / 28)$ & \\
\hline \multirow[t]{3}{*}{ DNMT-3B } & Negative & $11.6 \%(8 / 69)$ & $10.0 \%(4 / 40)$ & \multirow{3}{*}{$\begin{array}{l}\text { No significant difference } \\
\text { between grade I vs. II }\end{array}$} \\
\hline & Low & $24.6 \%(17 / 69)$ & $35.0 \%(14 / 40)$ & \\
\hline & High & $63.8 \%$ (44/69) & $55.0 \%(22 / 40)$ & \\
\hline
\end{tabular}

*For simplification, only the significant $p$ values are provided.

\section{Expression of DNMT-1 protein}

The majority of the cases of meningioma in each grade showed immunopositivity for DNMT-1 (96\% and $92.7 \%$, respectively) without any significant difference in frequency. However, strong immunoexpression was significantly more common in grade II cases as compared to their lower grade counterparts (87.8\% vs. 66.2\%; $p=0.040$ ) (Table III, Fig. 1). The cases with high expression of DNMT-1 showed a significantly higher proliferative activity as compared to the cases with negative/low expression (median \pm SD $-3.0 \pm 4.8$ vs. $2.0 \pm 2.9 ; p=0.024$ ). Strong expression of DNMT-1 was also found to be associated with higher incidence of brain invasion (26.5\% vs. $13.3 \%$; $p=0.206$ ). No other clinicopathological parameters showed a significant correlation.

\section{Expression of DNMT-3B protein}

Expression of DNMT-3B was detected in $89.4 \%$ (high expression - $66.7 \%$ ) of grade I and $90 \%$ (high expression $-55 \%$ ) of grade II meningiomas (Table III, Fig. 1). The immunohistochemical expression was not correlated with any of the clinicopathological parameters.

\section{Expression of DNMT- 3A protein}

Approximately $75 \%$ of cases of grade I and $61 \%$ cases of grade II meningiomas showed expression of DNMT-3A protein, out of which $41.7 \%$ and $46.4 \%$ showed high expression, respectively (Table III, Fig. 1).
The expression of DNMT-3A was not associated with any of the clinicopathological parameters.

\section{Correlation between expression of EZH2, H3K27me3, and DNMTs}

The expression of EZH2 showed a significant positive correlation with DNMT-3A. All EZH2-positive cases also showed expression of DNMT-3A. Furthermore, $75 \%$ of these positive cases had a strong expression. In contrast, approximately $30 \%$ of the EZH2-negative cases also showed negativity for DNMT-3A, while high expression was present only in $38 \%$ cases. No significant correlation was identified amongst other markers.

\section{Survival analysis}

Follow-up data were available in 89 cases. Eight of the cases died within four weeks of surgery. These cases were excluded from the survival analysis. The follow-up period of other cases ranges from 8.9 to 258.4 weeks. Out of the 81 cases, 15 showed evidence of recurrence or died. Grade II tumour was associated with shorter survival as compared to their grade I counterparts (mean PFS - 161.4 vs. 222.9 weeks; $p=0.07$ ). The cases that underwent sub-total resection had significantly shorter PFS as compared to cases with total/near total-resection (mean PFS 213.2 vs. 56.2 weeks; $p=0.001$ ). The skull-base tumours showed a shorter survival as compared 
to convexity/spinal tumours (mean PFS - 154.0 vs. 220.4 weeks; $p=0.06$ ). The younger patients had a better outcome in terms of PFS as compared to the older age group (mean PFS - 184.5 vs. 246.1 weeks; $p=0.13$ ). No significant association of PFS was identified with other pathological parameters. Among the epigenetic markers, assessed EZH2 and H3K27me3 showed a significant correlation with survival in univariate analysis. The cases with $\mathrm{EZH} 2$ expression showed a significantly shorter survival as compared to EZH2-negative cases (mean PFS 135.4 vs. 223.7 weeks; $p=0.007$ ). Similar trends were also observed in each grade separately; however, the value did not reach statistical significance (grade II-mean PFS 134.7 vs. 165.6 weeks; $p=0.07$; grade I-mean PFS 95.5 vs. 225.3 weeks; $p=0.47$ ). In contrast, cases with loss of H3K27me3 staining had a relatively shorter survival as compared to cases with retained expression (estimated mean PFS - 131.1 vs. 217.04 weeks; $p=0.03$ ). There was no significant association of H3K27me3 within grade II tumours when assessed separately. No correlation of survival with expression of DNMT$1,3 \mathrm{~A}$, and $3 \mathrm{~B}$ was identified. On multivariate analysis, extent of surgical resection and EZH2 expression were significantly associated with significantly associated with PFS (Table IV, Fig. 2).

\section{Discussion}

There is a plethora of data related to the various genetic aberrations in meningeal tumours from high-throughput genomic analysis. However, the clinically relevant predictive and prognostic biomarkers are limited. In contrast to genetic analysis, the epigenetic alterations are less well elucidated in meningiomas and mostly limited to the assessment of promoter methylation status of various genes [11]. Recently, six different prognostic subgroups were identified based on genome-wide DNA methylation profiles of 497 cases of meningioma that showed distinct molecular profiles, biological behaviour, and patient outcome [19]. This classification system appeared to be superior to the conventional WHO grading for prognostic stratification of meningiomas. Another study also described two molecular prognostic subgroups (favourable and unfavourable) based on the methylation status of 89 cases of meningiomas [14]. Hence, the analysis of DNA methylation status has evolved as a promising adjunct to the WHO classifications. In the present study, we analysed the expression of DNMTs, which are the major regulators of global CpG methylation status. All three important DNMT proteins were documented to be expressed in the majority of the meningioma cases irrespective of histological grades, indicating its crucial role in the pathobiology of meningiomas. However, apart from DNMT-1, which had significantly higher expression in grade II tumours, none showed any correlation with the histological grade. Furthermore, no association of DNMTs with survival was identified.

The other important arm of the epigenetic system, i.e. histone modification, is relatively less explored in meningiomas as compared to the DNA methylation. One recent study analysed the immunohistochemical expression of the important histone marker H3K27me3 in various grades of meningiomas. They found a significantly higher frequency of immunonegativity in grade II meningiomas as compared

Table IV. Univariate and multivariate analyses of association of various parameters with PFS (Cox proportional hazards regression model)

\begin{tabular}{|lccc|}
\hline Parameters & \multicolumn{2}{c|}{ Univariate analysis } & \multicolumn{1}{c|}{ Multivariate analysis } \\
\cline { 2 - 4 } & $\mathrm{HR}(95 \% \mathrm{Cl})$ & $p$-value & $\mathrm{HR}(95 \% \mathrm{Cl})$ \\
\hline Age (young vs. old) & $4.68(0.61-35.67)$ & 0.13 & - \\
\hline Site (non skull base vs. skull base) & $1.42(0.68-2.9)$ & 0.34 & - \\
\hline Types of surgical resection (GTR/NTR vs. STR) & $8.30(2.41-28.56)$ & 0.001 & $18.96(4.17-86.17)$ \\
\hline WHO grade (I vs. II) & $2.55(0.91-7.12)$ & 0.07 & $1.24(0.35-4.46)$ \\
\hline H3K27me3 expression (negative vs. positive) & $0.24(0.07-0.87)$ & 0.03 & $0.70(0.14-3.42)$ \\
\hline EZH2 expression (negative vs. positive) & $4.07(1.46-11.34)$ & 0.007 & $5.29(1.04-26.84)$ \\
\hline DNMT-1 expression (negative vs. positive) & $-{ }^{*}$ & 0.68 & - \\
\hline DNMT-3A expression (negative vs. positive) & $0.39(0.06-2.34)$ & 0.30 & - \\
\hline DNMT-3B expression (low/negative vs. high) & $0.53(0.11-2.68)$ & 0.45 & - \\
\hline
\end{tabular}

*No event was recorded in DNMT-1-negative cases. 

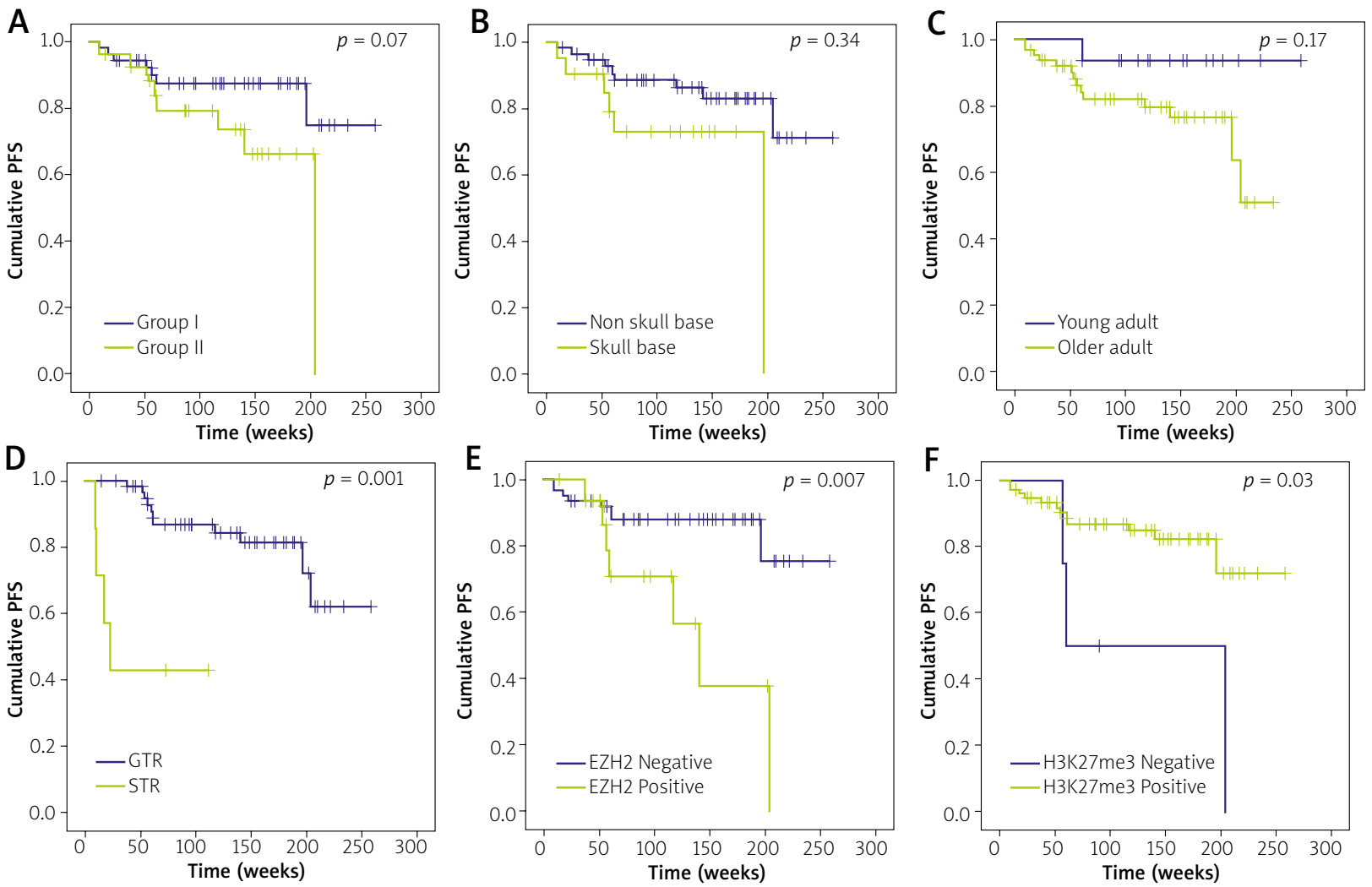

Fig. 2. Progression-free survival (PFS) represented by Kaplan-Meier plots for WHO grade (A), location (B), age (C), extent of resection (D), EZH2 expression (E), and H3K27me3 loss (F).

to their lower grade counterparts (11.6\% vs. $2.1 \%$ ). Loss of H3K27me 3 was associated with significantly shorter survival in grade I/II tumours. Interestingly, immunohistochemical expression H3K27me3 also correlated with the methylation-based prognostic subgroups of meningioma. The loss of trimethylation mark was significantly more prevalent in more aggressive subgroups, including intermediate $B$ and malignant [7]. The present study also documented an association of H3K27me3 loss with higher histological grade, proliferative activity, and shorter survival. Various previous studies have also documented the correlation of $\mathrm{H} 3 \mathrm{~K} 27 \mathrm{me} 3$ expression with EZH2 in malignancies $[2,5,13]$. Furthermore, transcriptional evidence of increased PRC2 activity has recently been documented in one of the aggressive subsets of anaplastic meningiomas [3]. Hence, in the present study we assessed the immunohistochemical expression of EZH2 for the first time in meningioma. Expression of this protein appeared to be of immense importance in the context of meningioma biology. EZH2 immunopositivity was associated with higher histological grade, necrosis, and proliferative activity. Interestingly, cases of grade II meningioma that were morphologically indistinguishable from grade I tumours, apart from invasion, were more similar to their lower grade counterpart in respect to EZH2 immunopositivity. More importantly, EZH2-positive cases were significantly associated with patient outcome in both univariate and multivariate analysis. However, no significant correlation was identified between the expression of EZH2 and H3K27me3 in the present study. On the other hand, EZH2 expression showed a significant positive correlation with the expression of DNMT-3A, a de novo methyltransferase, thus indicating a mechanistic link between DNA methylation and histone modification system. The association of DNMTs with EZH2 has already been described in other tumours and cell lines including gliomas [6,22]. The expression of H3K27me3 may be related to other PRC components including EED and SUZ-12, as documented in malignant peripheral nerve sheath tumour [17]. However, these mechanistic links between the above-men- 
tioned molecules cannot be established only based on the immunohistochemical expression data and need to be validated in in vitro studies.

\section{Conclusions}

The present study documented epigenetic dysregulation in meningiomas that possibly play a crucial role in determining the biological behaviour of the tumour. The expression of the epigenetic markers EZH2 and H3K27me3 emerged as important prognostic biomarkers. Although subgrouping of meningiomas based on the whole genome methylome profiling is one of the robust methods for prognostic stratification, it is costly and requires high throughput technologies; hence, it is not amenable to routine practice in most laboratories throughout the world. On the other hand, analysis of EZH2 and H3K27me3 is based on immunohistochemistry, which is pathologist-friendly and can easily be incorporated in routine practice as an adjunct to routine histopathology-based grading. Lastly, specific inhibitors against DNMTs and EZH2 are available and are being used in various clinical trials. These molecules may be important therapeutic targets in meningioma also.

\section{Ethical approval}

All procedures performed in studies involving human participants were in accordance with the ethical standards of the institutional ethics committee (All India Institute of Medical Sciences, Bhubaneswar) and with the 1964 Helsinki declaration and its later amendments or comparable ethical standards. Ref No. - T/IM-NF/Patho/19/50.

\section{Acknowledgements}

The authors are thankful to Dr. Suvradeep Mitra for helping in the scoring of immunohistochemistry in the discrepant cases. The authors are also thankful to Mr. Rehaman for technical help in the immunohistochemistry.

\section{Disclosure}

The authors report no conflict of interest.

\section{References}

1. Cao R, Wang L, Wang H, Xia L, Erdjument-Bromage H, Tempst P, Jones RS, Zhang Y. Role of histone $\mathrm{H} 3$ lysine 27 methylation in Polycomb-group silencing. Science 2002; 298: 1039-1043.
2. Chase A, Cross NC. Aberrations of EZH2 in cancer. Clin Cancer Res 2011; 17: 2613-2618.

3. Collord G, Tarpey P, Kurbatova N, Martincorena I, Moran S, Castro M, Nagy T, Bignell G, Maura F, Young MD, Berna J, Tubio JMC, McMurran ChE, Young AMH, Sanders M, Noorani I, Price SJ, Watts C, Leipnitz E, Kirsch M, Schackert G, Pearson D, Devadass A, Ram Z, Collins VP, Allinson K, Jenkinson MD, Zakaria R, Syed K, Hanemann CO, Dunn J, McDermott MW, Kirollos RW, Vassiliou GS, Esteller M, Behjati S, Brazma A, Santarius T, McDermott $U$. An integrated genomic analysis of anaplastic meningioma identifies prognostic molecular signatures. Sci Rep 2018; 8: 13537.

4. Goldbrunner R, Minniti G, Preusser M, Jenkinson MD, Sallabanda K, Houdart E, von Deimling A, Stavrinou P, Lefranc F, LundJohansen M, Moyal EC, Brandsma D, Henriksson R, Soffietti R, Weller M. EANO guidelines for the diagnosis and treatment of meningiomas. Lancet Oncol 2016; 17: e383-391.

5. Han Li C, Chen Y. Targeting EZH2 for cancer therapy: progress and perspective. Curr Protein Pept Sci 2015; 16: 559-570.

6. Harmancı AS, Youngblood MW, Clark VE, Coşkun S, Henegariu O, Duran D, Erson-Omay EZ, Kaulen LD, Lee TI, Abraham BJ, Simon M, Krischek B, Timmer M, Goldbrunner R, Omay SB, Baranoski J, Baran B, Carrión-Grant G, Bai H, Mishra-Gorur K, Schramm J, Moliterno J, Vortmeyer AO, Bilgüvar K, Yasuno K, Young RA, Günel M. Integrated genomic analyses of de novo pathways underlying atypical meningiomas. Nat Commun 2018; 9: 16215.

7. Katz LM, Hielscher T, Liechty B, Silverman J, Zagzag D, Sen R, Wu P, Golfinos JG, Reuss D, Neidert MC, Wirsching HG, Baumgarten P, Herold-Mende C, Wick W, Harter PN, Weller M, von Deimling A, Snuderl M, Sen C, Sahm F. Loss of histone H3K27me3 identifies a subset of meningiomas with increased risk of recurrence. Acta Neuropathol 2018; 135: 955-963.

8. Lee W, Teckie S, Wiesner T, Ran L, Prieto Granada CN, Lin M, Zhu S, Cao Z, Liang Y, Sboner A, Tap WD, Fletcher JA, Huberman KH, Qin LX, Viale A, Singer S, Zheng D, Berger MF, Chen Y, Antonescu CR, Chi P. PRC2 is recurrently inactivated through EED or SUZ12 loss in malignant peripheral nerve sheath tumors. Nat Genet 2014; 46: 1227-1232.

9. Louis DN, Ohgaki H, Wiestler OD, Cavenee WK (eds.). WHO Classification of Tumours of the Central Nervous System. $4^{\text {th }}$ ed. IARC, Lyon 2016; 231-244.

10. Louis DN, Perry A, Reifenberger G, von Deimling A, FigarellaBranger D, Cavenee WK, Ohgaki H, Wiestler OD, Kleihues P, Ellison DW. The 2016 World Health Organization Classification of Tumors of the Central Nervous System: a summary. Acta Neuropathol 2016; 131: 803-820.

11. Murnyák B, Bognár L, Klekner Á, Hortobágyi T. Epigenetics of meningiomas. Biomed Res Int 2015; 2015: 532451.

12. Nekrasov M, Klymenko T, Fraterman S, Papp B, Oktaba K, Köcher T, Cohen A, Stunnenberg HG, Wilm M, Müller J. PCl-PRC2 is needed to generate high levels of H3-K27 trimethylation at Polycomb target genes. EMBO J 2007; 26: 4078-4088.

13. Nichol JN, Dupéré-Richer D, Ezponda T, Licht JD, Miller WH Jr. H3K27 methylation: a focal point of epigenetic deregulation in cancer. Adv Cancer Res 2016; 131: 59-95. 
14. Olar A, Wani KM, Wilson CD, Zadeh G, DeMonte F, Jones DT, Pfister SM, Sulman EP, Aldape KD. Global epigenetic profiling identifies methylation subgroups associated with recurrence-free survival in meningioma. Acta Neuropathol 2017; 133: 431-444.

15. Ostrom QT, Gittleman H, Liao P, Vecchione-Koval T, Wolinsky Y, Kruchko C, Barnholtz-Sloan JS. CBTRUS Statistical Report: Primary brain and other central nervous system tumors diag nosed in the United States in 2010-2014. Neuro Oncol 2017; 19 (Suppl 5): v1-v88.

16. Purkait S, Jha P, Sharma MC, Suri V, Sharma M, Kale SS, Sarkar C. CDKN2A deletion in pediatric versus adult glioblastomas and predictive value of p16 immunohistochemistry. Neuropathology 2013; 33: 405-412.

17. Purkait S, Sharma V, Kumar A, Pathak P, Mallick S, Jha P, Sharma MC, Suri V, Julka PK, Suri A, Sharma BS, Sarkar C. Expression of DNA methyltransferases 1 and $3 \mathrm{~B}$ correlates with $\mathrm{EZH} 2$ and this 3-marker epigenetic signature predicts outcome in glioblastomas. Exp Mol Pathol 2016; 100: 312-320.

18. Robertson KD. DNA methylation, methyltransferases, and cancer. Oncogene 2001; 20: 3139-3155.

19. Sahm F, SchrimpfD, Stichel D, Jones DTW, Hielscher T, Schefzyk S, Okonechnikov K, Koelsche C, Reuss DE, Capper D, Sturm D, Wirsching HG, Berghoff AS, Baumgarten P, Kratz A, Huang K, Wefers AK, Hovestadt V, Sill M, Ellis HP, Kurian KM, Okuducu AF, Jungk $C$, Drueschler K, Schick M, Bewerunge-Hudler M, Mawrin C, Seiz-Rosenhagen M, Ketter R, Simon M, Westphal M, Lamszus K, Becker A, Koch A, Schittenhelm J, Rushing EJ, Collins VP, Brehmer S, Chavez L, Platten M, Hänggi D, Unterberg A, Paulus W, Wick W, Pfister SM, Mittelbronn M, Preusser M, Herold-Mende C, Weller M, von Deimling A. DNA methylation-based classification and grading system for meningioma: a multicentre, retrospective analysis. Lancet Oncol 2017; 18: 682-694.

20. Sandoval J, Esteller M. Cancer epigenomics: beyond genomics. Curr Opin Genet Dev 2012; 22: 50-55.

21. Stone DS, Ganz PA, Pavlish C, Robbins WA. Young adult cancer survivors and work: a systematic review. J Cancer Surviv 2017; 11: 765-781.

22. Viré E, Brenner C, Deplus R, Blanchon L, Fraga M, Didelot C, Morey L, Van Eynde A, Bernard D, Vanderwinden JM, Bollen M, Esteller M, Di Croce L, de Launoit Y, Fuks F. The Polycomb group protein EZH2 directly controls DNA methylation. Nature 2006 439: 871-874. 